\title{
Unravelling the Queer Space: Understanding Sexuality through the Works of Janice Pariat
}

\author{
Neha Grace Sajan \\ Post- Graduate Student \\ Masters in English with Cultural Studies \\ CHRIST (Deemed to be University) \\ Bangalore, Karnataka, India \\ nehasajan.393@gmail.com
}

Abstract

The project entitled "Unravelling the queer space: Understanding sexuality through the works of Janice Pariat" to examine the elements of sexual being from a queer perspective. There is always a politics that happens within the space of one's sexual and spiritual prominence. Thereby, a binary construction always happens and a stereotypical connotation happens for the same. Homosexuality is always subjected to suppression and non-normative within the society that upholds homophobia, heteronormativity and hetero-centrism. These are the results of the culturally imposed norms on the society. Understanding the deviance that happens in one's sexuality is an important area of concern. Talking about these aspects free from bias and prejudice is the freedom that can be gained. Society always has a violent approach towards people who deviate from the accepted norms leading to marginalization. One of the important factors that sideline with this idea is the impact of religion on an individual. Spiritual space and belief system are induced right from the childhood. Religious texts clearly define sexualities that deviate from the expected norms as abnormal or a taboo. The study is to break down the binary existence of one's sexual and spiritual space and how the deviance in sexualities pave way to attain a new spiritual growth. 
Keywords: Sexuality, Belief System, Homosexuality, Female Sexual Desire, Queerness And Feminist Politics, Queer Ecology.

Introduction

The concept of lesbianism does not just mean the attraction that two women share for each other. It is a word that undergoes lots of emotions which can define the multiplicity of meaning that two individuals, particularly women share. As we look at the history, we can see the problematic representation and consideration of the term Lesbian. This term was used as a self-defining term back then. Thereby, history shows a very wide categorization of the term, which comes under the aspects of sexuality of women and finally categorizing it under the umbrella term queerness or non-normative. Since then, this term puts forward the question of what exactly does the word mean, or it is normal to look at the homosexual attraction of women and thereby pointing that how can women look at their sexual desires from such a homosexual perspective. The models of the mid- $20^{\text {th }}$ century suggest the problematic situation of the women where, the so-called heteronormative relationships paved way for emotional frustration and lack of sexual satisfaction. The Freudian model which is developed in the 1960's talks about the idea of desire in an individual. Freud thereby talks about the concept of desire with relation to a steam that is built up in a kettle. When the kettle bursts up, it comes out. Similarly, desires of an individual which they can't satisfy burst and seek for acceptance. This idea gained its acceptance, when lesbians and gay individuals voiced for their space in terms of pleasure, desires and the politics that happened further.

Adrinne Rich in the 1980, talked about the initial shift of the lesbian history where the idea of 'Lesbian Continuum'. Her essays “Compulsory heterosexuality and Lesbian Existence" there by talked about the idea of naturalness of homosexuality and that, there is innate lesbian behavior in all women. This further paved way to look at the concept of lesbian identity and homosexuality from a different perspective. This path thereby followed the 
history of lesbian women who followed a different identity. Then came the theorist Faderman, who tried to connect the history of lesbian with the present lesbian approaches and thereby got connected with the continuum model. The primary aim of the concept was to look at the idea of the emotional attachment of the women. Then came the theory of social constructionism which gained its popularity. This idea paved the way to look at various sexual identities that were not widely present which were done on the basis of the works Jeffery Week and Michael Foucault. This questioned the idea of looking and understanding sexuality through language and other mediums. They argued that sexualities can be derived and understood from different perspectives and to look at them from culturally- dominant perspectives. As we look at the history, stories try to focus on the friendship between two women, particularly between unmarried women, their relationships and the empowerment activities that are done for women rights. Then came the idea to look at the power ideology and sexual understandings. Later, homosexual identities were labelled as essential among the community and society.

The theorist Sedgwick came with the idea to look at sexualities from a multiplicity and to not look at it from a fixed position. It derived to the understanding that gender identity is not fixed but fluid. It bought the idea that individuals perform different variants of identities during different stages of time. Thereby, queer historians tried to look at the idea of performativity. Judith Butler thereby talked about the idea of gender as performative and fluid and thereby to look at gender and sexual identities from a different- perspectives that flows as time and space changes. The idea of queer space moved widely from the nonnormative understandings. It looked at the plastic nature of gender and sexuality. Then the queer theory changed widely to look at the transgender studies. As the queer theory continues to tell, the lesbian theory focused on the same-sex attraction of women, the love they share, which may or may not be physical. It was also said that many women, who did not satisfy 
their sexuality within the space of heteronormativity looked at lesbian sexual identity. women-women relationships thereby shifted from the non-normative ideas of understanding sexuality. Even in the midst of all the acts, lesbian relationships were always treated as unnatural. One of the most interesting changes that history bought is the significance of sexuality studies which bought a great change in studying gender and sexuality. One of the exciting changes this specific study bought is the approach of looking at these areas as a source of change. Usually, we see a situation of looking at the so-called heteronormative rules to look and analyze the society. But here homosexuality or the deviant sexual identities was taken as a tool for looking at sexuality from a nuanced perspective and thereby to see the change. With this came the idea of looking at the importance of a body. The body was considered as more holy and one's sexuality as more important than the norms set up by the society. The idea of same-sex love as a gift from God and not as a sin. It can be analyzed that women failed their love for another woman in spite of the fear of the society they live in. because society always treated women who loved other women as unnatural and abnormal. As queer theory states we could see the compulsory pointing of looking at compulsory heterosexuality and homosexuality as odd or unnatural. Looking at this aspect, certain other aspects like the religion, faith etc. that are built up by the society is acting as a hindrance to the way an individual wishes to look at their sexuality. So, we see the intervention of a lot of societal factors that act as a hindrance to the development of one's sexuality. Here, the environment in which we live plays an important role in the development of a child's sexuality. There are certain norms set up by the society which paves way for the child to look at heterosexuality as the only normative way of treating sexuality.

\section{Theoretical framework and Methodology}

This paper thus aims to look at the idea of sexuality from a nuanced perspective giving importance to lesbian sexual identity and thereby looking at the concept of spiritual 
sexuality. There are stereotypical ways of representing and treating lesbian stories. Most of the time the stories are looked at from the perspective of violence and un-naturality. This sort of portrayal is always harmful and thereby propagating false notions of sexuality. Stories which talk about pure intimate lesbian relationships are very few. Such stories can bring change in understanding sexuality from a genuine perspective. This paper will address the questions on the evolving belief system of one's sexual and spiritual space exploring the areas of homosexuality, female sexual desire with a philosophical touch to it in-cooperating the ideas of queer sexuality. The stereotypical beliefs on homophobia and same sex love have suppressed the minority groups leading to sexual subalternity. These areas would be analyzed to bring new possibilities of understanding sexual space through the works of Janice Pariat. This paper will look at the works of Janice Pariat who gave an opened and nuanced approach to homosexual writings that are free from the so-called stereotypical portraying. The book "Boats on Land" will be analyzed from a queer perspective by incorporating the idea of conflicting space of belief system and sexuality. When belief systems talk about homosexual relationships as unhealthy, the works like this are sincere contributions in respecting and normalizing these varied range of sexualities. Thereby, a fluid approach of one's sexual and spiritual space can be built. Sexuality is always fluid and the idea that it is always confined to heteronormativity is the effect of the social construction and the power position it holds in majority.

Queer understanding of sexuality

The stories analyzed in this paper portray a significant concept "Lesbianism". The word Lesbian undergoes various connotations right from the time it came into usage. Queer theory is one such area that makes the umbrella term for Lesbian Studies. As we study the history, it is evident that lesbian studies emerged as a movement of liberation. The term 'liberation' does make sense when topics like lesbian studies are put forward. Because, often 
lesbianism is always termed as queer. There is always a societal stigma that is associated with the same. Literature has paved way for the portrayal of such stories but often failed to express the true idea of same-sex love or homosexuality. Amongst those literary pieces, the one that shattered the existed stereotype behind the portrayal of lesbian stories is of Pariat's Boats on Land. The stories have a life of its own, with its at most nuanced and genuine perspective on the theme lesbianism.

"Queer reading has become the term for interpretive activities that undertake to subvert and confound the established verbal and cultural oppositions and boundaries between male/female, homosexual/heterosexual and normal/abnormal" (Abrams, p. 328).

This study points out the need of initial understanding of lesbianism. When the term undergoes too many odd understandings, it is important to accept and look at the term from a genuine perspective. Same-sex love is always portrayed in literature in a stereotyped manner. There is always an odd idea by portraying these themes with a criminal background and are always mis-represented. The stories Boats on Land and Secret Corridors are two stories that has an elegant portrayal of same-sex love. People always find hard to accept homosexuality same as that of heterosexuality. When the inbuilt stigma in representing these characters is broken, there is a pure bliss of a deviant sexual experience which is the prominent in these two stories of Pariat. Lesbian consciousness is a major element that makes this come out of the stereotypical representation in these stories. The author makes blends the theme of samesex love to blend with the ecology thus making the stories appealing to the readers.

The story Boats on Land is a first-person narrative, that portrays a female bonding between two girls. Two girls from two different places meet together in a tea estate in Assam and thus evolves the story and the development of female sexual bonding and Identity. The story talks about the lesbian encounter that happens between the two girls. The girl from 
Shillong addresses her discovery of her own sexuality and bonding. Two girls from two different places Shillong and Chandbari happen to meet together with their families on a vacation. The lifestyle and surroundings of tea estate managers' bungalows in Assam is opulent and magnificent. The old English style homes, the army of servants, and the luxury of a secluded tea estate are all unusually appealing. To the young adolescent, the surroundings seem to be mystical. The other girl, on the other hand, lives in the same world but is completely uninterested in it because she is trapped in her own thoughts. She is a visible disgrace to her parents, who are actively blaming her misbehaviour on her deceased mother. Her stepmother is a trendy Mishing tribal lady whose outfit makes the other girl feel selfconscious about her own mother, which is a common teen trait. Chandbari's atmosphere evokes both nostalgic and uplifting emotions. The girls are swept into a friendship of ease in this setting, where no questions are asked and no pretensions are to be hidden. The same sex relationships are always sensitive subject that need to be handled with delicacy. The friendship, that both of them share influence them in deep ways. They unknowingly share a bond which is so deep and thereby they look forward to meeting in the river bank, where most of their conversations happen.

As the story begins, there is no trace of lesbian nature from the characters. Pariat has not given names to the two female characters and that itself stands as an openness of the author in portraying these characters. This can also be taken as the author's approach of showcasing the reservation that happens and people who deviate from the so-called normal sexuality do express their varied nature of sexuality. The initial part of the story clearly portrays that the narrator is not interested to come to Assam, instead she had plans with her friends at Shillong.

“... and during the winter vacation we had plans to visit each other's houses and make trips to Police Bazar to eat momos at Peking Restaurant and cream bun's at Floury's. 
More than the culinary delights, though it was a chance to meet boys, walk past them as though we didn't care what they were watching, be approached and asked if we'd like to go to Ward's Lake for a boat ride, or to Udipi Hotel for a coffee. There was a whole world waiting to be explored...One boy in particular filled my waking hours with lucid daydreams. His name I'd recently discovered was Jason; he had longish brown hair that fell over his eyes, and wore a striped flannel scarf with elan. This love affair, of secret smiles and glances, however, would have to wait" (Pariat 182).

This description that the narrator gives about her crush and her interest in boys clearly indicate that she is not a lesbian. This is how Pariat as an author stand entirely different from the other writers who portray same-sex narratives. Be it in literature, movies or anything there is always a negative connotation that begins with the queer people. This initial description of the narrator itself is an understanding that people are not born as lesbian. As the story emerges it can be seen that it is the different encounter or bonding with the girl from Chandberi that makes the narrator to have a female bonding, which can be portrayed as a lesbian relationship.

“"'Lesbian" describes a relationship in which two women's strongest emotions and affections are directed toward each other. Sexual contact may be a part of the relationship to a greater or lesser degree, or it may be entirely absent. By preference the two women spend most of their time together and share most aspects of their lives with each other" (qtd in Zimmerman 457).

When the narrator gets chances to spend time with the girl from Chandberi, she starts experiencing a new feeling which she had never experienced before. This experience changes her perception of receiving the world that surrounds her. Both the girls are on their journey of finding and experimenting their love. Sexual identity is not fixed. It has a fluid nature and changes accordingly. This fluidity can be seen in the narrator's experience with the other girl. 
Similarly, sexuality is not something that is fixed right from the birth. As defined by Lillian Faderman, sexual contact may be a part of the relationship. Here, the narrator has a sexual relationship with the other girl which adds more essence to their bonding. Pariat has beautifully portrayed the essence of their love with utmost sincerity.

"You stood behind me and started unbuttoning my nightdress. I began to protest...Held by a stare, by your hands, quick and cold through the fabric. When it dropped to the ground you asked me to step into the tub. I did...In a moment you were out of your T-shirt and jeans. We fit snugly, like twins. Then you soaped my back, my shoulders, my hair. I did the same for you... We lay there perfectly still, until the water cooled. The next day, the world was washed anew" (Pariat 195-196).

'The world was washed anew' signifies the narrator's new experience of her sexuality. It denotes that her perception of the world has changed and is no longer old but new. Pariat has made a beautiful attempt in portraying same-sex love even without any sort of negativity attached to it. Through these characters the author is actually asking the readers to view sexuality as an experience which changes one's perception of the world and themselves. Sexuality is not a construct that needs mere sexual satisfaction in a relationship. The narrator in the story is a true lover of nature. There is minute yet strong points that dwell deep into the bonding of the two characters in the story. Narrator relates her sexual space with the ecology that surrounds her. She resembles the days spent with her with the minute detailing of nature. When I think of you now, it feels of wet sand and long grass that comes to me, the smell of cigarettes, and cloves and creatures that live close to water (Pariat 199). Creatures that live close to water feels a fluid bond attaching to them and immersing themselves in the vast space that water bodies create. Similarly, the narrator compares her feeling with the girl as a vast space that brought her nuanced wide experience. The usages like flick of a page, sip from a glass that the narrator describes are mannerisms and gestures that denote their love 
making experience which was for a short period of time, yet the most -strongest of emotions. The story has a detailing of nature that blends with the experience of her sexuality that she experienced in the tea estate. There was nothing that stood odd to the readers and that is the success of the story.

The initial conversations or encounter between the two characters were not smooth. The lines that describe the bathtub scene clearly showcase the bonding of two. There was a naturality to the scenario. The purest form of physical attachment was detailed perfectly that did not separate homosexuality from the dominant heterosexual narratives. The usage, 'we fit snugly like twins' could clearly denote the emotional and physical connection that both shared. This also points out an attachment that is more than love. The kind of emotion they conveyed goes beyond the stereotypical physical relation. This sort of narration makes this story different. Author has smoothly produced the connection that happens between two souls and not two bodies to a greater point. This also says that sexuality is not something that is just related to one's body. But at a greater amount, It's the wider perspective an individual experiences through a bonding that helps them to see and approach the world in a nuanced perspective.

There are significant metaphorical and simile usages that the narrator used to describe emotional bonding between them. "Every night we'd curl around each other in the bathtub, like river reeds, the water deep and warm around us. Sometimes, down my neck, you traced the stars. Sometimes you spoke about your mother" (Pariat 198). We see the significance of nature in all of the narrator's descriptions. This indicates that one's sexuality can be closely knit to nature. Similarly, focusing on the idea of considering one's sexual space that goes beyond the boundaries of the body. All the minute representations and memories that the narrator creates with her female partner is detailed with absolute delicacy and the emotions go subtle every time. This narrative technique that Pariat has used gives a space to the readers 
to go beyond sexual space to understand the concept of love and belongingness. There is a strong bond between the two girls that is closely related to nature. There is the representation of the imagery of dragonfly which is metaphorical in nature which indicates the lifespan and the future of the relationship they share.

"I can measure our days together by the number of times we went to the river. Ten in fourteen days. Which by most accounts is not long, yet a dragonfly, you told me, may live for only twenty-four hours, and if we were dragonflies we would have spent ten lifetimes together" (Pariat 181).

"At night, the field could have been a shimmering body of water, the way the grass rippled silver in the pale moonlight. The countryside silence was pierced only by the steady chirrup of crickets. We lay in the field, undiscovered in our kingdom of weeds" (Pariat 191).

The poetic representation of nature in the above-mentioned lines symbolizes the mind of the two girls in the story. Nature thereby plays an important role in the blooming relationship. Nature adds color to the bond they share. Teenage is a time where emotions are always conflicting and the excitement about love will always be at its peak. We can clearly see the quest for love of the girl, how excited she is about the relationships, body and sexual feelings and thereby accepting herself. Even when the story ends by the separation of two girls, there is a sense of satisfaction and self -discovery in their lives. Both characters in the story are unnamed. One is riding high on a wave of adolescent fantasies about boys and endless ramblings, while the other is mentally scared by her mother's suicide. The latter is the daughter of an Assamese tea estate manager. All she might possibly want her Shillong friend is to be enthralled by her. There is a difference between a house and a housekeeper. She feels pampered while staying in the Assam bungalow. She has the impression that there are unseen hands lurking around the home, doing all the work. While they were eating breakfast, unseen 
hands made their beds and cleaned their rooms. As if all of this wasn't fascinating enough, the Shillong girl meets her "older mate," who fascinates her in the most surprising way, and she allows herself to be guided. Even though her stepmother and father are continually irritated by her actions, she is rebellious and unconcerned with their opinions. The love they have for each other is providing the readers a queer space; a space which plays an important role in their relationship. It is clearly evident that nature plays a significant role in building their love.

Teenage attitudes toward sexuality are primarily influenced by the home environment, and they evolve based on knowledge shared by peers. Parents play a critical role in creating a conducive environment at home for adolescents. This period is the journey of transition. Parents play a pivotal role in choices that the teenage takes on the concept of sex. More than the parents, they choose to take the opinion of their friends. The teens in the story tend to have a shady sexual relationship and depend on each other for deep comfort. These lesbian relationships are always treated as odd because of the societal take on these deviant relationships. The instances in the story indicate that the girls are afraid to keep up their relationship. This societal stigma is the reason for the confusion that happens in the same-sex relationships. The experiment of love in Boats on Land led two people on their search for self-awareness. Chandbari takes on the role of a microcosm of a future that the girls would have loved to inherit for the rest of their lives. The defiant reticence of one and the coiled-up coyness of the other combine to form a new friendship brimming with pleasure and comfort. About the fact that the girls will have to return to their previous lives, the love story that the romance spins leave a taste of silent defiance.

"Women, in particular, appear to regard sexuality from a relational orientation in which sexuality is viewed as one aspect of an intimate relation" (Waite \&Joyner 2001). 
Here, we see the two girls share an intimate relationship which gives a new meaning to their life. Nature plays a significant role in shaping their sexualities. Everything that Pariat describes in shaping their characters are connected closely to nature. We feel that nature welcomes their relationship by being part of their love.

The silent homophobia

The other story that goes with the detailing is Pariat's Secret Corridor. One of the important elements this story brings out is 'lesbian consciousness'. The story thus gives a conscious approach of the narrator in establishing a relationship with another woman, who is her classmate. This story happens around the girl named Natalie, who studies in a convent school in Shillong. Natalie makes constant efforts to make a bond with her female classmate. We can see the psyche of a girl who urges for her sexual fulfilment in Natalie. The title 'secret corridors' also denotes the secret psyche that Natalie holds thereby the title of the story is symbolic. Natalie maintains a feeling that is more than just a friendship, which she feels can't be revealed to any of her fellow classmates. She strongly seeks a bonding with the girl named Iba that shows her sexual space she urges for. This sort of fascination that Natalie has is not just an admiration that started but the constant and unchanging feeling for Iba that makes her sexuality go wild. This sort of sexual feelings of Natalie clearly indicates that she has a lesbian sexuality which she is urging from her partner Iba.

"That morning the world had shrunk to the size of a mole. A small, chestnut coloured spot to the left of a cupid's bow that dropped elegantly away from a soft and full middle. It was a mouth that made Natalie think of forbidden things... That morning, the intricacies of chemistry didn't interest her as much as Iba's mouth; and the face to which it belonged, she thought was just as attractive" (Pariat 80).

The above- mentioned lines describe a homo-erotic feeling that Natalie has for Iba. These lines indicate that the feeling that Natalie has for Iba is far more than a friendship. The 
story begins with these lines, where Natalie admires the beauty of her mole and mouth indicates the strong urge of feelings that goes through Natalie. At the same time Natalie does not share her feelings with anyone else and this gives an indication that Natalie herself feels that her feelings and attraction for Iba is odd or unusual. This inner feeling that Natalie has is a result of the stereotype that is built over time. Because, people who deviate from the norms will be considered as odd. This inner guilt restricts Natalie from sharing her feelings. The author has detailed the feelings of Natalie in the following lines.

"She (Natalie) longed to wipe the streaks of dirt from Iba's cheek, to tuck a stray curl behind her ear. Iba was exuberant, her hair wild and undone, her eyes shining with delight... She pretended to nip at Miranda's hand, then stopped in front of Natalie and brushed the tip of her tongue against Natalie's cheek. It was an electric shock; Natalie's stomach fluttered, something inside her constricted like a coiled snake" (Pariat 91).

These lines clearly indicate the wave of emotions that Natalie goes through during the playful act. Natalie is an eighth standard student. She is in her early stages if understanding her sexuality and these reactions that Natalie has project her lesbian sexuality. Pariat has done brilliant attempts to portray the innermost feelings that Natalie goes through. Natalie makes sincere attempts to seek the companionship of Iba and feels desperately low when Iba fails to have the same feelings for her. As the story progresses, we can see a bond that happens between Natalie and Carmel. Carmel is one of her classmates who undergoes the same set of emotional background as that of Natalie. Here, both of them love and like each other. Eventually, a sudden friendship and emotional bonding happens between the two and the connection grows stronger which is so intimate. There are instances in the story that indicates that the bonding they share is not just emotional but physical too. 
“Carmel put her hand on Natalie's knee. Her fingers felt hot against her skin. She leaned in closer, her hair undone, framing her face. Natalie closed her eyes before their lips met. It was nothing like she'd ever felt before. A low roar filled her ears, as though she was listening to a shell and could hear the sea. Something inside her unraveled, it uncoiled to the floor, and filled the room, every inch of its dusty corners. The world, with its scorn and derision, receded, and she was left with Carmel's mouth, which was soft and warm and tasted of tears. For a moment, the ghosts around them, and within, fell silent" (Pariat 94).

The above-mentioned lines describe the love making scene between the two girls. It all started with a friendship and eventually the bonding gets stronger and their feelings take shape emotionally and physically. The important element is that the two girls undergo some internal trauma which eventually binds them together. When Natalie failed to get the attention from Iba, she became low. Carmel could satisfy the feelings that Natalie was seeking for. Both Carmel and Natalie have a quest for care and attention which is far more than just a friendship and the instances clearly portray their lesbian sexuality. Pariat genuinely portrayed the feelings that two girls and she clearly shows that same-sex relationships are empowering to a great extent. Natalie was low due to the trauma that was haunting her, but Carmel could give her a better environment.

“... a woman's status is not solely determined by her relationship to a male-dominated society and literary culture... that strong female ties are important in women's lives, and that a woman's sexual and emotional orientation has a profound impact on her consciousness and thus her creativity" (Zimmerman 452).

Pariat makes a genuine approach in showcasing the feelings from Natalie's perspective which is not hetero-normative in nature. Here, we see the bond that Natalie builds with Carmel helps her to overcome the loneliness that the society gives her. In a way society 
is also responsible in side lining the people whose sexuality is homosexual in nature. This inner feeling portrays the idea of 'homophobia' which is indirectly shown to the readers. Pariat has done such approaches to make sure to convey the same-sex love in its purest form and not something odd or abnormal. Pariat through Nathalie has made the point that women not only seek attention from men all the time. There are instances when two women share an intense bonding of each other that is healthy and satisfying. Society always acts as a hindrance to these minorities and labels them as odd which is an important point of concern. The author has neatly showcased the idea of homosexuality with no prejudice and stereotype in a society where heteronormativity is praised.

As we see, literature that portrays same-sex love are very few. Even then it portrays homosexuality as a sin or violence and heteronormativity as the ablest part of the society. Therefore, people whose sexualities are deviant are always mis-represented.

Pariat in one of her interviews on Boats on Land talked about her thought process in writing the book. She began writing the love story between a girl and a boy and she felt wrong. She said that there was something original that was lacking in her narrative. Then she started writing the story of two girls and she felt that right. It is always about how one perceives the concepts. Here, Pariat breaks down the binary and construct to showcase that same-sex can also be portrayed beautifully. Gender as always is a social construct in which people impose the stereotype of a majority thereby playing a power position. Even within the representation of queer love, there is a dominating position one character holds over the other. The stories of Pariat are different from this power positioning. There is no such dominating characterisation that happens; two characters share equality in their characteristics by providing individual space. These minute aspects make the stories worth meaningful. Sexual identity is not something that is rigid but fluid in which an individual's sexual and spiritual space gains satisfaction. 
Adolescents will learn a lot from romantic relationships about communication, sentiment, empathy, identity, and (for certain couples) sex. These lessons are important contributors to development, resilience, and satisfaction in the teen years, as well as a crucial basis for long-term relationships in adulthood. Having a girlfriend or boyfriend in puberty will increase one's self-esteem. Youth are happy with themselves when their relationships are marked by intimacy and open contact. Young people place a high emphasis on the encouragement, confidence, and intimacy they find in intimate relationships. In reality, teen conflicts are more common with their parents and peers than with romantic partners, while romantic relationship tension grows with age. This sort of intimacy is what we see in Natalie's character. When she couldn't get the love back from Iba, she felt depressed. This depression makes her feel detached from the life she is living. Natalie is in her age where she is trying to find her sexual preference. So, she wanted the love and care of her partner and she failed to get that. Instead, Carmel understands her emotions and loves her to bring her back from the trauma she was living. Young couples value spending time together doing things that both parties enjoy. Relationships often end where this layer of intimacy is absent. Intimacy is an important aspect in every relationship. when the care and love for each other is lost, then the emotional bonding is lost. This emotional bonding creates the physical and mental attachment of two individuals who share love for each other. Relationships can help in sexual maturity, which is a vital aspect of maturation. Many teenagers agree that sex can take place in the form of an intimate relationship, and while not all relationships are physical, the majority of sexually engaged teenagers are monogamous. Relationships, of course, have their drawbacks. When you enter the realm of marriages, you nearly always end up in the physically insecure situation of breaking up. Breaking up can cause self-doubt and despair in young people who are more vulnerable to rejection. Low-quality relationships marked by a 
lack of confidence, persistent tension, and dating abuse can lead to depression and anxiety in young people.

Meeting respective partners is difficult for sexual minority teens. Although many teenagers meet their intimate partners at graduation, sexual minority youth are less likely to do so, considering the amount of harassment they face and the limited number of young people who have come out. Natalie in her surrounding faces this sort of rejection and thereby she fails to express her love for Iba in public due to the fear of internal homophobia. She fears that same-sex love is will always create a negative impact in her life. This sort of internal homophobia is the result of the social stigma associated with homosexuality. The majority of a child's peers would be of the same gender. When a child reaches puberty, he or she has a strong interest in sexual relationships. Crushes appear in the pre- and early teen years, though there may be no interaction with the object of infatuation. Similarly, we see the female characters in Pariat's stories building an emotional intimacy and bonding with the female friends. Individuals in their early adolescence, especially those with a high social status, often socialise in mixed-gender groups outside of school. They then start dating in short-term relationships, frequently following in the footsteps of their most famous peers.

Young teenagers gain trust by dabbling in intimate waters while surrounded by good friendships. In time, self-assurance encourages teenagers to defy peer pressure and select romantic partners based on compatibility rather than social attractiveness. Throughout adolescence, the average length of teenage sexual relationships grows. Relationships last six months on average by the age of 16 , and a year or more by the age of 18 , with black teenagers maintaining longer relationships than other racial or ethnic groups. The nature of teenage romantic relationships is influenced by the amount of closeness and guidance they have received from their parents and siblings. Parents should create an environment for their children and make them understand the need to accept every gender and sexuality with 
respect and to not look at varied sexualities with prejudice. Children should be taught to learn what gender and sexuality is and how one's sexuality is different from the other. Teenage is the time when youths try to find a relationship with their own body, mind and sexuality. By understanding their sexuality, they should be able to find connection with their own spiritual space. Spiritual space should be in connection with the belief systems one holds to establish their lifestyle and not the elements of social construction.

To some degree, the nature of romantic relationships reflects the quality of friendships: teens who have near and trusting friendships are more likely to have close and trusting romantic relationships, while those who are hostile and aggressive with friends and peers will carry these traits into relationships. Relationship consistency is often influenced by perceived social expectations. For example, if boys think that violence is normal among their peers, they are more likely to be hostile romantic partners. Here, it is important to understand any relationship free of power positionings. There is always a binary construction that happens within a relationship which showcase toxic masculinity and patriarchy which is the result of social stigma surrounding the same. Families may also help their children have stable marriages by embracing non-heterosexual orientations by treating their children's same-sex romantic partners the same way they approach their opposite-sex romantic partners. Adults could be needed to assist lesbian and gay teenagers in seeking safe places to meet and socialise. This social environment can thereby create an atmosphere of genuine and pure way of accepting sexual preferences.

\section{Conclusion}

This paper tried to look at the aspects of sexuality and spirituality from a varied angle through the works of Janice Pariat. One of the primary areas of the paper was to select an author who perceive sexuality, particularly lesbian relationship and female sexual desires from a more genuine and nuanced perspective. Pariat is one such individual who gives a 
closer analysis on the ideas of lesbian relationships. She has viewed female relationships from a point that is usually different from the stereotypical portrayal. The characters of the selected stories are genuine portrayal of the female relationships. What makes her works different from the already build notions is to perceive lesbian relationships as natural and normal. The idea of natural and normal is quite unusual when it comes to defining homosexuality. Any mediums such as novels, films etc. has a greater role in portraying clear images which is free from prejudice and biases. It is always seen that stories where homosexuality is portrayed always show case a violent imagery or negative attitude towards these communities. This stereotype creates a negative feeling in the minds of the people which in turn will create internal as well as external homophobia. Fear towards these community will create a negative belief system inside their community as well as in the majority circle of heteronormative people. So, the idea of compulsory heteronormativity is injected in the lives of the people. This creates the binary difference of normal and abnormal. So, it is important to look at what is normal and what is abnormal. There is no such idea of perceiving something as odd and unnatural. As per the norms set up by the society, anything that deviates from the normal set of rules set up by the society is termed as abnormal. The idea of the paper is to break the binary construction of heteronormativity and homosexuality. Binary construction is the most important thing to be shackled to bring forward the idea of accepting different variants of sexuality and gender identity.

Another area of concern, is to look the idea of construction of male and female binary in homosexual relationships. The stories of Pariat give a new understanding of the same. As a usual pattern, stories of homosexuality are portrayed with one person holding a power position over the other. It is the same as that of a male and female holding different power positions of their own. It is always stereotyped as male having a power position higher than the female counterpart. This sort of an approach can be seen in majority of homosexual 
stories where, one of the females would take up the position of male by holding masculine space and the other female a feminine space. There is a binary construction that happens in homosexual relationships which is an after effect of the constructed stereotype of the society. Such a binary construction is shackled in the stories of Pariat. Each female has a space of their own in the story giving equal power positioning and so, the relationship between the two is more welcoming. Similarly, lesbian relationships are always viewed as something where the attraction between the two females is always considered as physical. It is important to note that like any other relationship, there is always an effect of intimacy and emotional bonding between the two females. It is not always the physical relationship that dominates, but emotional bonding of two female protagonists is highlighted in the stories. The intimate scenes are shown with absolute naturality that the readers do not view the relationship as odd. Instead, there is a genuine approach that is given to the homosexual relationships in the stories. It talks about the emotional bonding and connection that happens between two female individuals which helps them to look at their life from a different perspective.

The idea is to break the binary understanding of viewing homosexual relationships from a prejudiced belief system. The instances in the stories give a spiritual understanding to the sexuality that the protagonists hold within their life. Thereby, the paper tried to view spirituality as an entity that is closely connected to one's sexuality. It can be noted that sexuality and spirituality are two important aspects of an individual space and are no longer two different entities. Then, we see the importance of the body in sexuality. The aspect of desire has an important role while discussing the elements of sexuality and spirituality. Desires are closely related to an individual's body and mind. People choose their sexuality according to their desires of the mind and body. So, the mind and body are closely related to each other. The stories Boats on Land and Secret Corridors shows such connection between 
mind, body and nature. Thereby, a clear aspect of understanding nature and sexuality could be seen.

What we choose to become is always related to where we belong to. Such relation is widely seen in Boats on Land where the two protagonists share their love in relation to nature. Nature plays an important role in their relationships. This is where we can see the connection between mind body and nature and how a relationship is closely connected to nature. The aspect of spirituality is brought to shackle the idea of traditional notions of belief system in relation to the institution of religion. The social construct of religion should be shackled to bring nuanced ideas in understanding spirituality and sexuality not as separate entities. Spirituality and belief systems are thereby the moral values and the perspectives that an individual holds to have a satisfied life of their own. In such cases, the body and desires are closely connected. If one tends to have a queer sexuality, it is the understanding an acceptance of their body to perceive their sexuality as queer. Everyone has the right to look on to their sexualities. It is to be noted that no one is born queer, but rather it is their living space that makes them understand their need of sexuality and that examines their preferable sexual and spiritual space. Spiritual and sexual space should not be fixed but they are fluid and changes with time and space. Therefore, one's sexual and spiritual space are far different from the institutional belief systems. These institutional beliefs setups are mere social constructs and not a fixed system of norms that need to be practiced. It is high time to view and perceive one's desires and accept homosexual relationships free of prejudice and stereotypes. The involvement of religion and the surroundings we live in are very important. Then further, there is a point in which individuals start analyzing their own need and start appreciating their deviant sexual identity. When this acceptance happens, the idea of faith and identity changes. Then, there is the personalized way of looking at one's sexual and spiritual space beyond the confinements of the belief system. 
Through these characters the author is actually asking the readers to view sexuality as an experience which changes one's perception of the world and themselves. Sexuality is not a construct that needs mere sexual satisfaction in a relationship. The narrator in the story is a true lover of nature. There is minute yet strong points that dwell deep into the bonding of the two characters in the story.

As we see in the stories, the two female protagonists get back to their normal lives with so many memories they had together. This shows the emotional bonding that is created between the two individuals which is free from the biases of gender and sexuality. It is important to view relationships not only from a physical perspective but rather as some strong bonding that two people share together to make their life better. Childhood and adolescence refer to the period from birth to the emergence of adulthood, which the committee considers to be in the early twenties. During this stage of life, an individual transforms from a dependent infant to a self-sufficient adult, regardless of sexual orientation or gender identity. The developmental changes that occur are complicated, particularly when it comes to the initial stages of teenage life. It is important to accept individuals who accept the sexuality of their own. It is important to look at the difference in sexuality of each individual that is free from the social stigma. Many youths are unsure of their sexuality particularly due to their lack of understanding. On the other hand, the innate fear restricts them from making their sexuality visible. Sexuality is a fluid entity and accepting and understanding sexuality from a nuanced perspective is important and thatis normal. 


\section{References}

(PDF) Queer Theory, Sexuality and Religion.

Www.researchgate.net/publication/290760786_Queer_theory_sexuality_and_religion. Beagan, Breanda. “(PDF) Religion, Spirituality, and LGBTQ Identity Integration.” ResearchGate, 2015, www.researchgate.net/publication/276119041_Religion_Spirituality_and_LGBTQ_Id entity_Integration.

Boats on Land: a Collection of Short Stories, by Janice Pariat, Random House India, 2012. Brenda, Beagan. "LGBTQ Experiences with Religion and Spirituality: Occupational Transition and Adaptation." Taylor \& Francis, 2015, www.tandfonline.com/doi/abs/10.1080/14427591.2014.953670.

Cravens, Royal G. "The Politics of Queer Religion: Politics and Religion.” Cambridge Core, Cambridge University Press, 15 Apr. 2018, www.cambridge.org/core/journals/politics-and-religion/article/politics-of-queerreligion/330F293B5BD898A91D404D4207B574B6.

Experiments with Love: Janice Pariat's Boats on Land. nehu.ac.in/public/downloads/Journals/Journal_VolXIII_No2_Jul-Dec2015_A7.pdf.

Freeman, D.J. The Intersectionality of Gender, Sexuality, and Religion . 2020, www.researchgate.net/profile/NilMutluer/publication/337811479_The_intersectionality_of_gender_sexuality_and_reli gion_novelties_and_continuities_in_Turkey_during_the_AKP_era/links/5deb5152a6f dcc28370c3784/The-intersectionality-of-gender-sexuality-and-religion-novelties-andcontinuities-in-Turkey-during-the-AKP-era.pdf.

From Sex to Superconsciousness, by Osho, Tao Pub., 2002. 
Goswami, Harajit. July 2017 - The Criterion: An International Journal in English. 2017, www.the-criterion.com/july-2017/.

H, Goswami. ISSN 2278-9529 Galaxy: International Multidisciplinary . 2017, www.thecriterion.com/V8/n8/IN04.pdf.

Haggerty, A.J. Sacred Shame: Integrating Spirituality and Sexuality. 2017, sophia.stkate.edu/cgi/viewcontent.cgi?article $=1748 \&$ context $=$ msw_papers.

“Knowing Gays and Lesbians, Religious Conflicts, Beliefs about Homosexuality.” Pew Research Center - U.S. Politics \& Policy, Pew Research Center, 31 Dec. 2019, www.pewresearch.org/politics/2015/06/08/section-2-knowing-gays-and-lesbiansreligious-conflicts-beliefs-about-homosexuality/.

Mackenna, C. Sexuality and Spirituality - Possible Conjunctions. 2019, www.rcpsych.ac.uk/docs/default-source/members/sigs/spirituality-spsig/chrismackenna-sexuality-and-spirituality-asp.pdf?sfvrsn=dd694e64_2.

Matty, M.R. Faith and Homosexuality: Grace, Religious Problem-Solving ... 2014, scholar.utc.edu/cgi/viewcontent.cgi?article=1003\&context=honors-theses.

Rosario. Sexual Identity Development among Lesbian, Gay, and ... 2006, www.jstor.org/stable/20620226.

Tate, Charlotte Chuck. “Considering Lesbian Identity from a Social-Psychological Perspective: Two Different Models of 'Being a Lesbian.'” Journal of Lesbian Studies, U.S. National Library of Medicine, 2012, www.ncbi.nlm.nih.gov/pubmed/22239449.

Wheeler, H. Sexuality \& Religion: How Devoutly Religious Lesbian, Gay ... 2013, repository.asu.edu/attachments/110615/content/Wheeler_asu_0010N_13032.pd 